\title{
Pasteurella multocida peritonitis in a CAPD patient case report and a review of literature
}

\begin{abstract}
Bacterial peritonitis is a common complication in CAPD patients. Skin bacteria such as Staphylococci are most usually found in PD peritonitis cultures. Also Streptococci and Gram negative rods are found. Pasteurella multocida is an aerobic Gram negative coccobacillus found as natural oral flora in cats and dogs and other domestic and wild animals. We report a patient who developed peritoneal dialysis associated peritonitis induced by Pasteurella multocida, that was isolated from de dialysis effluent. This pathogen is very unfrequent in CAPD infections, in the literature there are about 33 cases. This is the first case reported in Argentina. ${ }^{1}$
\end{abstract}

Keywords: peritoneal dialysis, pasteurella multocida, peritonitis
Volume 8 Issue 4 - 2020

\author{
Mastrapasqua Sonia, Martinez M Carolina, \\ Calfunao Daniel \\ Servicio de Nefrologia, Hospital Provincial Neuquen, Dr Castro \\ Rendon, Argentina
}

Correspondence: Mastrapasqua Sonia, Servicio de Nefrologia, Hospital Provincial Neuquen, Dr Castro Rendon, Argentina,Tel 54- 9 299-4490834, Email smastrapasqua@gmail.com

Received: March 18, 2020 | Published: August 17, 2020

\section{Introduction}

Pasteurella multocida is a fermentative Gram negative coccobacillus often found in upper respiratory tracts of wild and domestic animals. It can cause infections in humans (specially soft tissues, as a result of scratchs or bites). ${ }^{2,3}$ However it can be isolated in cases of pneumonias, lung abscess, and meningitis and very rarely in spontaneous peritonitis in cirrhotic patients. In the literature there are few cases (about 33) of peritonitis associated to CAPD caused by to this bacteria. This is the first case of Pasteurella multocida peritoneal dialysis-associated peritonitis reported in Argentina.

\section{Case Report}

A 39-year-old male with a history of morbid obesity (BMI 44) hypertension and nephrotic syndrome in CAPD during four years was admitted to our hospital, complaining of intense abdominal discomfort and turbid peritoneal effluent. Physical examination revealed abdominal tenderness and rebound. His temperature was $38.5^{\circ} \mathrm{C}$, his blood pressure was $140 / 80 \mathrm{~mm} \mathrm{Hg},{ }^{4}$ heart rate 90 beats/ min. The peritoneal catheter did not show evidence of damage, tunnel or exit site infection. Laboratory tests showed white blood cells of 160 cells $/ \mathrm{mm}$ in the fluid analysis (70\% neutrophils). The patient was treated under suspicion of peritonitis of unknown origin. Initial empiric therapy consisted in Vancomycin 1g IP and gentamicin I.P (he had a history of MRSA in cultures of a vascular graft infection and skin lesions). After 48 hours, the patient did not show improvement neither in the aspect of peritoneal fluid, nor in the abdominal pain..$^{5,6}$ White cells number increased to $12700 / \mathrm{mm}^{3}$. Bacteriologists informed that a Gram negative coccobacillus was growing in the cultures and that characterization of the bacteria was very difficult, probably a Pasteurella. The antibiotic schedule was changed to ceftriaxone I.P. The sample was sent to Malbran Institute in Buenos Aires where the bacteria was confirmed as Pasteurella multocida, subspecie septica isolated from the peritoneal effluent. After the switch in the antibiotic treatment abdominal findings and discomfort disappeared, and the white cells in the peritoneal fluid diminished to $5600 / \mathrm{mm}^{3}, 250 /$ $\mathrm{mm}^{3}$ and $140 / \mathrm{mm}^{3}$. In about 8 days. After two weeks of antibiotic therapy peritoneal effluent was turbid once again and cells were 210/ $\mathrm{mm}^{3}$, finally the catheter was removed and patient was transferred to hemodyalisis.?

\section{Discussion}

Peritonitis is a common complication of peritoneal dialysis, infections are originated in skin and then track along the catheter in most cases. In these patients infections with Gram positive cocci such as Staphylococcus epidermidis and aureus are frequently observed. Another frequent pathophysiological mechanism is transmural migration of intestinal bacteria due to intraabdominal pathology. It has been described that bacteria of zoonotic origin are a rare cause of peritonitis in PD patients. Pasteurella multocida is a Gram negative coccobacillus first identified in diseased birds in $1878 .{ }^{8}$ It is usually found in normal flora of cats (70-90\% colonization) and dogs (50$60 \%$ ). It is associated with skin and soft tissue infection following animal bites or scratches. It has also been described as a cause of cellulitis, osteoarthritis, meningitis, pulmonary infections and sepsis. Rarely it has been reported in bacterial spontaneous peritonitis in cirrhotic patients and originating peritonitis in PD patients. To date 33 cases have been published of Pasteurella multocida peritonitis in patients in PD, usually in APD. In some cases there is a history of pet bites, licks or scratches and fluid leakage. It is probable that the length of tubes used in the cycler and the longer time of exposure to the environments are risk factors in APD. Long tubes seem to be attractive toys for cats which can contaminate them. In our case line puncture or leak could not be documented, but transmission of the $P$. multocida to the patient hands of dialysis bags or tubes could occur from his pets.

In Hospital Provincial Neuquen, Pasteurella is isolated in soft tissues infections and blood cultures with a very low incidence (less than one case/year). In the section of Bacteriology of our laboratory about 17.000 samples a year are processed, so this is rarely a very unfrequent microorganism. There is a study in our country in 2006 characterizing 30 Pasteurella strains isolated from human and animal samples. (ANLIS, Administracion Nacional de Laboratorios e Institutos de Salud, Dr. Carlos G. Malbran). 8 of them were infections in humans associated with skin wounds, thorax abscess, pneumonia and bacteriemia. To our knowledge this is the first case of $P$. multocida peritonitis in a PD patient reported in Argentina.

\section{Conclusion}

We report an unfrequent case of peritonitis due to Pasteurella 
multocida in a PD patient. Many people have pets at home, so it is important to consider they can carry these oropharyngeal pathogens and the possibility of contamination of hands and dialysis supplies. It should be emphasized to mantain strict hygienic measures, hand washing and keeping domestic animals away from PD catheters, bags or tubs and not allowing them to stay in the room during exchanges.

\section{Acknowledgments}

None.

\section{Conflicts of interest}

The author declares there is no conflict of interest.

\section{References}

1. Fernández Giron F, Martin JM, Gómez ER, et al. Simultaneous streptococcus canis and Pasteurella multocida Peritonitis in a Peritoneal Dialysis Patient. Perit Dial. 2017;37(4):483-484.

2. Kim I, Kim YJ, Chung S et al. Cat-induced Pasteurella multocida peritonitis in continuous ambulatory peritoneal dialysis. Kidney Res Clin Pract. 2014;33:65-67.
3. Cooke FJ, Kodjo A, Clutterbuck EJ, et al. A case of Pasteurella multocida peritoneal dialysis-associated peritonitis and review of the literature. Int J Infect Dis. 2004;8(3):171-174.

4. Poliquin PG, Lagace-Wiens P, Verrelli M, et al. Pasteurella species peritoneal dialysis-associated peritonitis. Household pets as a risk factor. Can J Infect Dis Med Microbiol. 2015;26(1):52-55.

5. Satomura A, Yanai M, Fuyita T, et al. Peritonitis associated with Pasteurella multocida: molecular evidence of zoonotic ethiology. Ther Apher Dial. 2010;14(3):373-375.

6. Dressselars HF, Zwart B, Petterson A et al. Peritoneal dyalisis-associated peritonitis of zoonotic origin, when minor gets major. Netherlands Journal of Med. 2014;72(10):551-553.

7. Guilbert M, Zogheib E, Hchikat A, et al. Fatal multifocal Pasteurella multocida infection:a case report. BMC Res Notes. 2015(8):287-290.

8. Leotta GA, Vigo GB, Chinen I et al. Identificación, biotipificación y caracterización de cepas de Pasteurella multocida aisladas en la Argentina. Rev Arg Microbiol. 2006;(38):125-129. 